\title{
Performance of aluminium formate in removal of colloidal latex particles from industrial wastewater
}

\author{
Marja Mikola*, Juha Tanskanen ${ }^{\#}$
}

\author{
Chemical Process Engineering Research Unit, Faculty of Technology, P.O. Box 4300, FI-90014 \\ University of Oulu, Finland \\ * Corresponding author. Tel. +358 29448 2565; E-mail address: marja.mikola@oulu.fi \\ \# E-mail address: juha.tanskanen@oulu.fi
}

\begin{abstract}
The coagulation efficiency of novel coagulant aluminium formate was studied in the treatment of highly contaminated effluent from a styrene butadiene latex manufacturing plant. The coagulation behaviour of the aluminium formate was compared to the behaviour of the commonly used polyaluminium chloride and aluminium sulphate. The effects of the coagulant type and dose and coagulation $\mathrm{pH}$ on the treatment efficiency were studied as well as the role of polyacrylamide coagulant aid. Floc separation was done using three different methods: sedimentation, filtration and centrifugation. Their functionality was evaluated as part of the coagulation performance studies. Good purification results were obtained with all of the tested coagulants, the lowest residual turbidities achieved being 0.7 NTU with aluminium formate, 1.4 NTU with polyaluminium chloride and $0.7 \mathrm{NTU}$ with aluminium sulphate. It was also observed that aluminium formate is as effective as commercial coagulants and is thus a potential novel coagulant chemical due to its less harmful and biodegradable counter anion. When using only aluminium coagulants, flocs were found to be too fine to be removed by sedimentation but they could be effectively removed by filtration or centrifugation. The use of polyacrylamide was found to be useful in the sense that it enables the separation of flocs by simple sedimentation because the floc size is significantly increased. In this study new knowledge about the coagulation behaviour of of highly contaminated effluent from latex manufacturing was gained and aluminium formate was proved to be promising coagulant also in industrial effluent treatment.
\end{abstract}

\section{Keywords}

Coagulation; Aluminum formate; Industrial wastewater; Colloidal latex removal; Coagulant aid 


\section{Introduction}

Coagulation is the most broadly applied method in water [1] and wastewater [2] treatment. In coagulation, small impurity particles are combined into bigger and more easily removable aggregates with the help of chemicals. Coagulation is commonly used in the purification of surface water to be used as potable or process water. In addition to this, coagulation is very often a part of the treatment process for industrial effluents. Coagulation has been studied broadly in the treatment of effluents for example from the pulp and paper industry [3], textile industry [4], tanneries [5], distilleries [6], petrochemical industry [7] and palm oil mill industry [8]. In industrial effluent treatment, coagulation is often used to remove such impurities that either cannot be removed with biological treatment or are harmful to its operation.

Coagulants are typically aluminium- or iron-based compounds. The popularity of aluminium and iron as coagulation chemicals is due to their ability to form both highly charged cations and hydroxide precipitates in water. Highly charged cations can effectively neutralise the surface charge of the impurity particles, which enables them to unite and thus form more easily separable flocs. The forming hydroxide precipitate effectively binds impurities to itself and thus forms larger removable aggregates. [9] Beside metal coagulants, organic polyelectrolytes can also be used as coagulants. The most commonly organic polyelectrolytes are used as a coagulant aid to increase the size and density of the flocs formed with metal coagulants. [10]

Aluminium and iron salts such as aluminium sulphate and ferric chloride are the most typically used metal coagulants. Nowadays prehydrolysed compounds, most commonly polyaluminium chloride, are also widely used. Aluminium formate is a novel coagulant chemical in which the formate anion is used to replace chloride or sulphate as a counter anion to aluminium. Formate has some advantages over chloride or sulphate. For example, it is less corrosive than chloride [11], which makes it safer for process equipment. Formate is also a biodegradable anion, which is a beneficial property if aluminium formate is used in wastewater treatment because anions from the coagulant are removed during the biological treatment often used in both industrial and municipal wastewater treatment. Formate can also act as a carbon source in biological treatment, which may enhance the performance of the biological treatment especially if the treated water does not otherwise contain enough carbon. Earlier, aluminium formate has been studied only in the treatment of surface water [12-14]. No previous studies on the use of aluminium formate in industrial effluent treatment have been published.

Styrene butadiene latex is the most commonly used binder in the pigment coating of paper and board industry because of its good binding power. Styrene butadiene latex is produced by emulsion polymerization. The impurities in certain effluents coming from emulsion polymerization consists of 
colloidal latex particles and some dissolved compounds which need to be removed before the discharge of the effluents. Latex particles should be removed from these effluents before their biological treatment because the high latex amounts may hinder the operation of the biological process. Only a few studies on the treatment of effluents from the polymer industry have been made and none of them is about the treatment of effluents similar to those treated in this study $[15,16]$.

In the present work, treatment of effluent collected from a latex manufacturing plant was studied. The coagulation performance of the novel self-prepared aluminium formate was evaluated and compared to traditional, commercially available polyaluminium chloride and aluminium sulphate. The effects of the coagulant type and dose on the treatment efficiency were studied. The impact of the coagulation $\mathrm{pH}$ and the use of polyacrylamide as a coagulant aid were also investigated.

\section{Materials and methods}

\subsection{Chemicals}

The aluminium formate used in this study was synthesised using aluminium hydroxide $\left(55.6 \% \mathrm{Al}_{2} \mathrm{O}_{3}\right.$ reagent grade, Sigma Aldrich) and formic acid (98\% (w/w), Riedel-deHaën, Reag. Ph. Eur.). A detailed description of the synthesis has been published earlier [13]. The coagulation performance of aluminium formate was compared to the coagulation performance of commercial aluminium sulphate (VWR BPH Prolabo AnalR Normalpur) and polyaluminium chloride (EKA WT91). For the jar tests, coagulants were diluted to an aluminium concentration of $20 \mathrm{~g} \mathrm{~L}^{-1}$. Commercial anionic polyacrylamide (EKA PL7450) was used as a coagulant aid in some of the experiments. The polyacrylamide was dosed as a $0.1 \%$ solution. For $\mathrm{pH}$ adjustment $1 \mathrm{M} \mathrm{NaOH}$ solution (prepared from $\mathrm{NaOH}$ pellets, VWR BDH Prolabo, AnalR Normalpur) was used. All the solutions were prepared in ultrapure water $(18.2 \mathrm{M} \Omega \cdot \mathrm{cm})$.

\subsection{Wastewater}

The treated wastewater was collected from a latex manufacturing plant. The wastewater contained high amounts of latex particles with a dry matter content of $1 \mathrm{w}-\%$ and turbidity of $17000 \mathrm{NTU}$. The $\mathrm{pH}$ of the water was 6.5. The collected effluent was part of the effluent stream generated on a manufacturing plant. 


\subsection{Coagulation tests}

The coagulation tests were conducted as jar tests with a six-paddle jar tester (Flocculator 2000, Kemira Kemwater). The jar tests were conducted with a sample amount of $800 \mathrm{~mL}$ at room temperature. At first, the water was mixed rapidly for $1 \mathrm{~min}$ at a speed of $400 \mathrm{rpm}$, during which the coagulant, as a solution containing $20 \mathrm{~g} / \mathrm{l}$ aluminium, was added and the $\mathrm{pH}$ was adjusted with a dropwise addition of $1 \mathrm{M} \mathrm{NaOH}$ solution. A VWR pHenomenal PC 5000H pH Meter using a VWR pHenomenal 111 electrode was applied for $\mathrm{pH}$ measurements. After rapid mixing, water was stirred at a speed of $20 \mathrm{rpm}$ for $15 \mathrm{~min}$ to achieve floc growth. In the tests where polyacrylamide was used, it was added at the beginning of slow mixing as a solution containing $0.1 \mathrm{w}-\%$ polyacrylamide. After slow mixing, the system was allowed to settle for $30 \mathrm{~min}$.

The amount of $150 \mathrm{ml}$ of the supernatant was taken for analysis from a depth of $10 \mathrm{~cm}$. The sample was divided into three subsamples, $50 \mathrm{ml}$ each. One of the subsamples was analysed as it was, the second was filtered through filter paper of pore size $40 \mu \mathrm{m}$ (Qualitative filter paper 417, VWR International) and the third was centrifuged using a Jouan C412 centrifuge with a relative centrifugation force of 560 g-units. The coagulation efficiency was evaluated with turbidity measurements. Most of the coagulation tests are single measurements but a few of them was made in triplicate. Based on these repetitions experimental error can be evaluated to be less than $5 \%$ when measured turbidity is $\geq 1000 \mathrm{NTU}$, and less than $10 \%$ when measured turbidity is < 1000 NTU.

\subsection{Turbidity measurement}

Turbidity was measured with a Hach Ratio/XR turbidity meter. The validity of the analyser was confirmed by measuring the Gelex turbidity standards once a day. The turbidity measurement was conducted by transferring the sample in the measuring cuvette and placing the cuvette in the measuring chamber of the analyser. The samples with turbidity over 2000 NTU was diluted with ultrapure zero turbidity water because the analyser does not detect turbidities above 2000 NTU. It was confirmed that the dilution factor does not affect to the turbidity value by measuring the diluted samples with different dilution factors. 


\section{Results and discussion}

\subsection{Effect of aluminium coagulant type, dose and $\mathrm{pH}$}

The effect of the coagulant type and dose was studied by conducting a series of jar tests with different coagulant doses with all three coagulants adjusting the coagulation $\mathrm{pH}$ to 6 . Residual turbidity values are presented in Table 1. In the tables coagulants aluminium formate, polyaluminium chloride and aluminium sulphate are referred to as $\mathrm{AF}, \mathrm{PAC}$ and $\mathrm{Al}_{2}\left(\mathrm{SO}_{4}\right)_{3}$, respectively.

During slow mixing, it was observed that some floc formation occurred in most of the tests. However, no settling occurred during the 30-minute settling time. It can be seen in Table 1 that the turbidity of the settled samples with all of the coagulants and at all the tested doses was even higher than the turbidity of the treated wastewater, which was 17000 NTU. The chance in turbidity values may be due to the fact that, even though no settling occurred, some changes in particle size and shape, which affect the scattering of light (17), occurred during coagulation.

The reason for the poor separation of the latex from the water even though visible floc formation occurred during the slow mixing stage could be that the formed flocs are quite small and the flocs are not heavy enough to settle within the used 30-minutes of settling time. Filtration and centrifugation were studied as separation methods to see if the formed floc could be more effectively separated using them than by sedimentation. Reduction in turbidity could not be achieved with filtration or centrifugation without using any coagulant. However, when using filtration or centrifugation after coagulation, good turbidity removal was achieved. It can be seen from Table 1 that when the aluminium dose used was big enough, low residual turbidity values were obtained using filtration or centrifugation as the separation method. The general trend was that with an increasing aluminium amount, the residual turbidity also decreased. With all of the tested coagulants it was also noticed that when the aluminium dose reached a certain value, the residual turbidity did not decrease further. The residual turbidities achieved were very low which indicates that big share of the particles have been removed and the matter left in the solution causing the residual turbidity cannot effectively be removed with coagulation even with high coagulant doses. Similar trend that the coagulation performance is not improving anymore after certain coagulant dose has been observed also in other studies for example in study conducted with industrial polymer effluent coagulation [16] and in surface water treatment with same aluminium formate used in this study $[12,13]$.

Some differences between coagulants and separation methods were observed in the amount of aluminium needed to achieve good removal of turbidity. When the separation of flocs was done by filtration, good latex removal from the water was achieved, especially with higher coagulant doses. 
It can be seen that, with the lowest tested coagulant dose, $25 \mathrm{mg} \mathrm{L}^{-1}$, residual turbidity remained high with all of the coagulants, but already at an aluminium dose of $50 \mathrm{mg} \mathrm{L}^{-1}$, a significant reduction in residual turbidity was obtained. In addition, some differences between the coagulants were observed. With aluminium formate and aluminium sulphate, residual turbidity deceased much faster with an increasing aluminium dose than with polyaluminium chloride. With aluminium formate and aluminium sulphate, an aluminium dose of $75 \mathrm{mg} \mathrm{L}^{-1}$ was enough to result in quite low residual turbidity whereas, with polyaluminium chloride, $100 \mathrm{mg} \mathrm{L}^{-1}$ was needed to achieve similar residual turbidity. When the achieved residual turbidity is considered at the dose range where the coagulants are working properly, that is the dose range of $75 \mathrm{mg} \mathrm{L}^{-1} \mathrm{Al}$ or higher, the lowest achieved residual turbidities was achieved with aluminium formate.

Using centrifugation as the separation method resulted in a similar overall trend to filtration, although some differences were observed. Additionally, aluminium formate and aluminium sulphate performed a bit better with centrifugation than polyaluminium chloride. With polyaluminium chloride, residual turbidity remained very high with lower aluminium doses. With aluminium formate and aluminium sulphate, some reduction in turbidity was obtained even with an aluminium dose of $50 \mathrm{mg} \mathrm{L}{ }^{-1}$, whereas $88 \mathrm{mg} \mathrm{L}^{-1}$ was needed in the case of polyaluminium chloride to obtain any reduction in turbidity. Furthermore, residual turbidity with this dose was also significantly higher than with the same dose of the other coagulants. With aluminium doses of $100 \mathrm{mg} \mathrm{L}^{-1}$ and higher, low residual turbidities were obtained with all of the coagulants and the lowest achieved residual turbidities were similar for all of the studied coagulants nevertheless so that the lowest residual turbitities were achieved with aluminium formate.

It can also be seen from Table 1 that when filtration and centrifugation are compared to each other regardless of the coagulant type and dose used, filtration results in lower residual turbidities than centrifugation. The differences between the separation methods were the most significant when the aluminium doses were quite small and thus the water probably contained a lot of small flocs and non-coagulated particles. The superior performance of filtration compared to centrifugation may be due to the fact that, with filtration, the forming cake also retains particles that are smaller than the pore size of the filter paper. On the other hand, particles as small as these cannot be separated with the centrifugation forces used. 
Table 1. Residual turbidity after coagulation with different coagulant doses at pH 6.

\begin{tabular}{|c|c|c|c|c|c|c|c|c|c|}
\hline \multirow{3}{*}{$\begin{array}{l}\text { Aluminium } \\
\text { dose }\left(\mathrm{mg} \mathrm{L}^{-1}\right)\end{array}$} & \multicolumn{3}{|c|}{ Settling } & \multicolumn{3}{|c|}{ Filtration } & \multicolumn{3}{|c|}{ Centrifugation } \\
\hline & \multicolumn{3}{|c|}{ Residual turbidity (NTU) } & \multicolumn{3}{|c|}{ Residual turbidity (NTU) } & \multicolumn{3}{|c|}{ Residual turbidity (NTU) } \\
\hline & $\mathrm{AF}$ & PAC & $\mathrm{Al}_{2}\left(\mathrm{SO}_{4}\right)_{3}$ & $\mathrm{AF}$ & PAC & $\mathrm{Al}_{2}\left(\mathrm{SO}_{4}\right)_{3}$ & $\mathrm{AF}$ & PAC & $\mathrm{Al}_{2}\left(\mathrm{SO}_{4}\right)_{3}$ \\
\hline 25 & 18660 & 20310 & 18870 & 17610 & 17400 & 15600 & 17940 & 18630 & 17850 \\
\hline 50 & 20340 & 21270 & 19830 & 830 & 6900 & 540 & 12000 & 19500 & 8730 \\
\hline 63 & 19770 & 21000 & 20100 & 270 & 7680 & 150 & 8430 & 18540 & 3900 \\
\hline 75 & 19500 & 21180 & 20120 & 23 & 3000 & 39 & 507 & 18030 & 721 \\
\hline 88 & 20400 & 21090 & 19860 & 8.3 & 3900 & 17 & 80 & 1150 & 130 \\
\hline 100 & 20130 & 21000 & 20160 & 1.0 & 31 & 17 & 34 & 75 & 66 \\
\hline 125 & 19830 & 19800 & 20730 & 1.5 & 15 & 5.5 & 26 & 32 & 35 \\
\hline 150 & 20160 & 18720 & 20370 & 2.6 & 19 & 3.9 & 22 & 32 & 32 \\
\hline
\end{tabular}

Table 2. Residual turbidity after coagulation at different $\mathrm{pH}$ with an aluminium dose of $100 \mathrm{mg} \mathrm{L}^{-1}$.

\begin{tabular}{|c|c|c|c|c|c|c|c|c|c|}
\hline \multirow[b]{3}{*}{$\mathrm{pH}$} & \multicolumn{3}{|c|}{ Settling } & \multicolumn{3}{|c|}{ Filtration } & \multicolumn{3}{|c|}{ Centrifugation } \\
\hline & \multicolumn{3}{|c|}{ Residual turbidity (NTU) } & \multicolumn{3}{|c|}{ Residual turbidity (NTU) } & \multicolumn{3}{|c|}{ Residual turbidity (NTU) } \\
\hline & $\mathrm{AF}$ & PAC & $\mathrm{Al}_{2}\left(\mathrm{SO}_{4}\right)_{3}$ & $\mathrm{AF}$ & PAC & $\mathrm{Al}_{2}\left(\mathrm{SO}_{4}\right)_{3}$ & $\mathrm{AF}$ & PAC & $\mathrm{Al}_{2}\left(\mathrm{SO}_{4}\right)_{3}$ \\
\hline 4 & 21660 & 20280 & 21210 & 1.4 & 94 & 35 & 41 & 64 & 51 \\
\hline 4.5 & 20610 & 21000 & 21180 & 8.1 & 120 & 41 & 52 & 80 & 43 \\
\hline 5 & 20880 & 21900 & 21000 & 6.0 & 102 & 8.6 & 31 & 65 & 27 \\
\hline 5.5 & 19890 & 19740 & 20100 & 4.8 & 22 & 6.4 & 30 & 48 & 36 \\
\hline 6 & 20130 & 21000 & 20160 & 1.0 & 31 & 17 & 34 & 75 & 66 \\
\hline 6.5 & 20100 & 21480 & 19590 & 42 & 61 & 27 & 249 & 504 & 378 \\
\hline 7 & 20040 & 20700 & 19230 & 251 & 1410 & 367 & 1440 & 14700 & 2290 \\
\hline
\end{tabular}

The effect of the coagulation $\mathrm{pH}$ for all of the tested coagulants was studied by using a constant aluminium dose of $100 \mathrm{mg} \mathrm{L}^{-1}$ and varying the coagulation $\mathrm{pH}$ by means of the addition of sodium hydroxide. The studied $\mathrm{pH}$ range was from 4 to 7 . The residual turbidities obtained in the $\mathrm{pH}$ tests are presented in Table 2.

Similarly to the coagulant dose studies, no reduction in turbidity was obtained with any of the tested coagulants when sedimentation was used as the separation method. However, in these tests also visible floc formation was observed during the slow mixing stage. The effect of $\mathrm{pH}$ on the coagulation performance can be seen from the residual turbidities obtained by using filtration or centrifugation as the separation method.

When using filtration as the separation method, especially with aluminium formate, very low residual turbidity values can be obtained. With $\mathrm{pH} 6$ or less, the residual turbidities achieved with aluminium formate were less than 10 NTU for the whole range, which means very high removal of latex particles. The lowest residual turbidity was obtained at a $\mathrm{pH}$ of 6 , but the differences between that and the residual turbidities achieved at a lower $\mathrm{pH}$ were so minor that the exact optimum $\mathrm{pH}$ 
could not be determined. With aluminium formate, when the $\mathrm{pH}$ was increased from 6 the residual turbidity was increased slightly at $\mathrm{pH} 6.5$ and more significantly at $\mathrm{pH}$ 7. With polyaluminium chloride, residual turbidities after filtration were higher than with aluminium formate and the optimal $\mathrm{pH}$ range was narrower. It was observed that the best removal efficiency was obtained at a pH between 5.5 and 6. In a low $\mathrm{pH}$ range from 4 to 5, residual turbidities were quite high and at $\mathrm{pH} 7$ they were even higher. With aluminium sulphate, quite low residual turbidities were obtained across the whole of the studied $\mathrm{pH}$ range, except for the highest $\mathrm{pH}$. For the whole range the removal efficiency of aluminium sulphate was better than with polyaluminium chloride but not as good as with aluminium formate. Especially at the lowest tested $\mathrm{pH}$ values aluminium formate gave lower residual turbidities than aluminium sulphate. The optimal $\mathrm{pH}$ for aluminium sulphate when using filtration as the separation method was found to be between 5 and 5.5, although the differences in the pH range below 7 were small.

When centrifugation was used as the separation method, fairly similar general $\mathrm{pH}$ dependence was observed as when using filtration. At most of the points, residual turbidities were higher also in these tests, similarly to the coagulant dose tests when centrifugation was used instead of filtration. It can be seen that with all of the coagulants removal efficiency was inadequate when the $\mathrm{pH}$ was 6.5 or 7 . At pH 6 or less, all of the coagulants worked quite similarly and no exact optimal pH could be seen when the $\mathrm{pH}$ was 6 or less for any of the coagulants.

At low $\mathrm{pH}$ aluminium forms positively charged species in water, and when the $\mathrm{pH}$ is increased to around six, part of the aluminium precipitates as aluminium hydroxide. Positively charged cations are effective in coagulation because they destabilise the negatively charged impurity particles. As for aluminium hydroxide, sweep flocculation occurs when impurity particles are embedded in the growing precipitate. [18] Because fairly good removal efficiencies was observed when the $\mathrm{pH}$ was 6 or below it indicates that both charge neutralisation and sweep flocculation may occur in treatment of this water. The reason for the quite high residual turbidities at $\mathrm{pH} 7$ is probably that at such a high $\mathrm{pH}$, significant part of the aluminium is in the form of negatively charged species [18], which are not effective in coagulation. Similar trends according to the $\mathrm{pH}$ dependence of the coagulation has been reported also when using aluminium sulphate in the treatment of similar but much lower initial turbidity containing polymer effluent [16].

\subsection{Effect of polyacrylamide}

The effectiveness of the polyacrylamide coagulant aid was studied to improve the poor sedimentation of the formed flocs, which was observed when only aluminium coagulants were used. Commercial 
anionic polyacrylamide was used in the tests. The compatibility of polyacrylamide with all three aluminium coagulants was evaluated. The effects of polyacrylamide amount and the coagulation $\mathrm{pH}$ were studied. In these tests, the quantity of aluminium coagulants used was $100 \mathrm{mg} \mathrm{Al} \mathrm{L}^{-1}$ and the $\mathrm{pH}$ was 6.

During the experiment where polyacrylamide was used, very distinct floc formation was observed during slow mixing at most of the experimental points. The formed floc was much bigger and also quite good sedimentation was observed with most of the polyacrylamide doses. The effect of the polyacrylamide dose on residual turbidities is presented in Table 3. It can be seen that when using polyacrylamide together with aluminium coagulants, low residual turbidities are also achieved when sedimentation is used as the separation method. When using polyacrylamide together with aluminium formate or aluminium sulphate, a significant decrease in residual turbidities was obtained when the amount of polyacrylamide was $8 \mathrm{mg} \mathrm{L}^{-1}$ or higher. When polyaluminium chloride was used as aluminium coagulant, quite a good reduction in turbidity was obtained even at a polyacrylamide dose of $6 \mathrm{mg} \mathrm{L}^{-1}$, but also with polyaluminium chloride the turbidity removal efficiency was still increased when the polyacrylamide dose was increased to $8 \mathrm{mg} \mathrm{L}^{-1}$. The lowest residual turbidities with sedimentation as the separation method were obtained with all of the tested coagulants when 10 $\mathrm{mg} \mathrm{L}^{-1}$ polyacrylamide was used as coagulant aid and there were no systematic difference between different aluminium coagulants used.

Although the main purpose of the polyacrylamide is to enable separation by sedimentation, it was also used together with other separation methods. With filtration, the use of polyacrylamide did not have a significant effect on the residual turbidity when using aluminium formate as the aluminium coagulant because the residual turbidity was also very low without the polyacrylamide. When polyaluminium chloride or aluminium sulphate was used as the aluminium coagulant, a slight decrease in residual turbidity was obtained when using polyacrylamide together with filtration. Even though the use of polyacrylamide had no or only a small effect on the residual turbidity, it is also notable that the increase in floc size caused by the polyacrylamide made the filtration much faster and prevented clogging of the filter. Also in the case of centrifugation, the polyacrylamide had only a small effect on the observed residual turbidities compared to the results achieved in same condition without polyacrylamide. 
Table 3. Effect of PAM dose on residual turbidity. Amount of aluminium coagulant used was $100 \mathrm{mg}$ $\mathrm{Al} \mathrm{L}^{-1}$ and $\mathrm{pH} 6$.

\begin{tabular}{|c|c|c|c|c|c|c|c|c|c|}
\hline \multirow{3}{*}{$\begin{array}{l}\text { PAM dose } \\
\left(\mathrm{mg} \mathrm{L}^{-1}\right)\end{array}$} & \multicolumn{3}{|c|}{ Settling } & \multicolumn{3}{|c|}{ Filtration } & \multicolumn{3}{|c|}{ Centrifugation } \\
\hline & \multicolumn{3}{|c|}{ Residual turbidity (NTU) } & \multicolumn{3}{|c|}{ Residual turbidity (NTU) } & \multicolumn{3}{|c|}{ Residual turbidity (NTU) } \\
\hline & $\mathrm{AF}$ & PAC & $\mathrm{Al}_{2}\left(\mathrm{SO}_{4}\right)_{3}$ & $\mathrm{AF}$ & PAC & $\mathrm{Al}_{2}\left(\mathrm{SO}_{4}\right)_{3}$ & $\mathrm{AF}$ & PAC & $\mathrm{Al}_{2}\left(\mathrm{SO}_{4}\right)_{3}$ \\
\hline 0 & 20130 & 21000 & 20160 & 1.0 & 41 & 17 & 34 & 75 & 66 \\
\hline 4 & 20100 & 20400 & 20700 & 5.2 & 1.2 & 1.7 & 41 & 70 & 80 \\
\hline 6 & 17190 & 1100 & 20100 & 0.7 & 1.4 & 0.7 & 38 & 68 & 69 \\
\hline 8 & 73 & 23 & 275 & 2.6 & 6.6 & 4.5 & 10 & 24 & 37 \\
\hline 10 & 21 & 20 & 50 & 4.8 & 6.9 & 8.8 & 7.3 & 15 & 29 \\
\hline 12 & 60 & 25 & 51 & 3.0 & 5.3 & 4.4 & 13 & 11 & 16 \\
\hline 14 & 39 & 43 & 59 & 14 & 11 & 11 & 21 & 20 & 20 \\
\hline
\end{tabular}

Table 4. Effect of $\mathrm{pH}$ on residual turbidity. Amount of aluminium coagulant used was $100 \mathrm{mg} \mathrm{Al}$ $\mathrm{L}^{-1}$ and PAM dose was $10 \mathrm{mg} \mathrm{L}^{-1}$.

\begin{tabular}{|c|c|c|c|c|c|c|c|c|c|}
\hline \multirow[b]{3}{*}{$\mathrm{pH}$} & \multicolumn{3}{|c|}{ Settling } & \multicolumn{3}{|c|}{ Filtration } & \multicolumn{3}{|c|}{ Centrifugation } \\
\hline & \multicolumn{3}{|c|}{ Residual turbidity (NTU) } & \multicolumn{3}{|c|}{ Residual turbidity (NTU) } & \multicolumn{3}{|c|}{ Residual turbidity (NTU) } \\
\hline & $\mathrm{AF}$ & PAC & $\mathrm{Al}_{2}\left(\mathrm{SO}_{4}\right)_{3}$ & $\mathrm{AF}$ & PAC & $\mathrm{Al}_{2}\left(\mathrm{SO}_{4}\right)_{3}$ & $\mathrm{AF}$ & PAC & $\mathrm{Al}_{2}\left(\mathrm{SO}_{4}\right)_{3}$ \\
\hline 4 & 20700 & 19230 & 21180 & 12 & 25 & 2.2 & 47 & 106 & 23 \\
\hline 5 & 20700 & 19890 & 20100 & 5.5 & 4.8 & 0.9 & 49 & 38 & 31 \\
\hline 6 & 21 & 20 & 50 & 4.8 & 6.9 & 8.8 & 7.3 & 15 & 29 \\
\hline 7 & 368 & 770 & 824 & 165 & 441 & 543 & 345 & 749 & 801 \\
\hline
\end{tabular}

The effect of the treatment $\mathrm{pH}$ was also studied when polyacrylamide was used. The residual turbidities are presented in Table 4. When sedimentation is used as separation method it can be seen that in these tests the $\mathrm{pH}$ has great effect to the treatment efficiency. It was observed that when the treatment $\mathrm{pH}$ was 5 or below, no removal of turbidity was achieved with any of the aluminium coagulants used together with polyacrylamide. When the $\mathrm{pH}$ was 6 , low residual turbidities were observed with all of the aluminium coagulants. At pH 6 part of aluminium forms aluminium hydroxide precipitate, which has positively charged surface [18]. The negatively charged polyacrylamide can effectively bridge together the positively charged aluminium hydroxide flocs [10], which may explain the good results obtained at $\mathrm{pH} 6$ with sedimentation when polyacrylamide is used. When the $\mathrm{pH}$ was increased to 7 , the observed residual turbidity was significantly higher with all of the aluminium coagulants than the corresponding turbidity at $\mathrm{pH}$ 6. At $\mathrm{pH} 7$, quite good floc formation was visually observed but there were also a lot of small particles that did not settle, which caused the quite high residual turbidities. The reason for this may be the same than without using the polyacrylamide discussed earlier that significant share of the aluminium is in form of negatively charged species, which are not effective in coagulation and thus big part of the latex particles, are not 
destabilised. Hence, the addition of negatively charged polyacrylamide does not enable the particles to unite.

When filtration or centrifugation was used in separation, the lowest residual turbidities were observed at $\mathrm{pH}$ 6. With these separation methods, good removal efficiencies were also achieved at lower $\mathrm{pH}$ values. Again, when the $\mathrm{pH}$ was increased to 7, residual turbidity was quite high. These $\mathrm{pH}$ trends are the same than observed without using polyacrylamide when filtration or centrifugation was used as separation methods. This indicates that when filtration or centrifugation is used the $\mathrm{pH}$ dependence of the treatment efficiency is mostly caused by the $\mathrm{pH}$ effects originated from the function of the aluminium coagulants and the addition of the polyacrylamide has no significant role with the pH dependence.

Based on the results obtained in this study, there are multiple process options that should be considered when designing a coagulation process to be used on industrial scale for the treatment of effluent from the latex industry. The use of only aluminium coagulants together with filtration or centrifugation could be one applicable process option that would minimize the chemical expenses of the process. On the other hand, the use of polyacrylamide as a coagulant aid would make separation easier but would also increase the chemical expenses. When using the coagulant aid, simple sedimentation could be used for separation and also using filtration would be simpler because larger flocs do not clog the filtration materials as much as finer flocs. One potential alternative to floc separation when polyacrylamide is used could also be the combination of sedimentation and filtration, where most of the flocs are removed by sedimentation and the rest by filtration. This would lengthen the lifetime of the filters because most of the flocs would be removed in sedimentation and ensure high removal because filtration is used to remove particles that cannot be removed by sedimentation. The selection of the process alternative is always case-specific and is influenced, for example, by the characteristics and volumes of the water to be treated and by the target cleanliness for the final effluent.

\section{Conclusions}

A study was made of the coagulation efficiency of novel aluminium coagulant, aluminium formate, for the treatment of effluent from the latex industry containing colloidal latex particles. Two commercially available aluminium coagulants polyaluminium chloride and aluminium sulphate was used as reference coagulants. The effect of the aluminium coagulant type and dose as well as the coagulation $\mathrm{pH}$ and use of polyacrylamide coagulant aid was studied. The effectiveness of three 
different separation methods, i.e. sedimentation, filtration and centrifugation, was evaluated in different coagulation conditions.

When using aluminium coagulants without the polyacrylamide coagulant aid, good removal efficiencies were obtained using filtration or centrifugation as the separation method. Due to the finesized flocs and small density difference between latex and water, separation was not achieved by sedimentation alone. At optimum treatment condition the use of aluminium formate was found to result the lowest residual turbidities. On the whole aluminium formate was found to be at least as efficient as the commercial reference coagulants although differences between the coagulants were quite small. The adequate amount of aluminium coagulant was found to be $100 \mathrm{mg} \mathrm{Al} \mathrm{L} \mathrm{L}^{-1}$ or slightly less, depending on the coagulant type. The optimal $\mathrm{pH}$ with all the tested coagulants was found to be between 5 and 6 .

Using polyacrylamide as the coagulant aid clearly increased the floc size and made the flocs easier to separate. When the coagulant aid was used, it was possible also to separate the flocs by sedimentation. All the tested aluminium coagulants behaved very similarly when they were used together with the polyacrylamide. The amount of polyacrylamide sufficient to enable sedimentation was found to be $8 \mathrm{mg} \mathrm{L}^{-1}$ and the $\mathrm{pH}$ should be 6 or below. The use of the coagulant aid did not significantly affect the residual turbidities achieved with filtration or centrifugation, although it made for example the filtration much faster.

Coagulation with aluminium coagulants was found to be an efficient treatment method for wastewater from the latex industry either alone or in combination with a polyacrylamide coagulant aid. The novel coagulant aluminium formate was found to be at least as effective as commercial aluminium coagulants. This makes it potential coagulant because the use of formate as counter anion has some advantages over sulphate and chloride due to for example the biodegradability of the formate anion. 


\section{References}

[1] C.Y. Teh, T.Y. Wu, The potential use of natural coagulants and flocculants in the treatment of urban waters, Chem. Eng. T. 39 (2014) 1603-1608.

[2] C.Y. Teh, P.M. Budiman, K.P.Y. Shak. T.Y. Wu, Recent Advancement of CoagulationFlocculation and Its Application in Wastewater Treatment, Ind. Eng. Chem. Res. 55 (2016) 43634389.

[3] D. Pokhrel, T. Viraraghavan, Treatment of pulp and paper mill wastewater - a review. Sci. Total Environ. 333 (2004) 37-58.

[4] A.K. Verma, R.R. Dash, P. Bhunia, A review on chemical coagulation/flocculation technologies for removal of colour from textile wastewaters. J. Environ. Manage. 93 (2012) 154-168.

[5] G. Lofrano, S. Meriç, G.E. Zengin, D. Orhon, Chemical and biological treatment technologies for leather tannery chemicals and wastewaters: A review. Sci. Total Environ. 461-462 (2013) 265-281. [6] A.K. Prajapati, P.K. Chaudhari, Physicochemical Treatment of Distillery Wastewater - A Review. Chem. Eng. Commun. 202 (2015) 1098-117.

[7] S. Verma, B. Prasad, I.M. Mishra, Pretreatment of petrochemical wastewater by coagulation and flocculation and the sludge characteristics. J. Hazard. Mater. 178 (2010) 1055-1064.

[8] K.P.Y. Shak, T.Y. Wu, Optimized use of alum together with unmodified Cassia obtusifolia seed gum as a coagulant aid in treatment of palm oil mill effluent under natural pH of wastewater Ind. Crop. Prod. 76 (2015) 1169-1178.

[9] C.C. Davis, M. Edwards, Coagulation with hydrolysing metal salts: Mechanism and Water quality impacts. Crit. Rev. Env. Sci. Technol. 44 (2014) 303-347.

[10] B. Bolto, J. Gregory, Organic polyelectrolytes in water treatment. Water Res. 14 (2007) 2302324.

[11] P. Hellstén, J. Salminen, K. Jørgensen, T. Nystén, Use of formate in road winter deicing can reduce groundwater deterioration. Environ. Sci. Technol. 39 (2005) 5095-5100.

[12] M. Mikola, J. Tanskanen, Preparation and coagulation performance of solid aluminium formate. J. Water Process Eng. 5 (2015) 1-5.

[13] M. Mikola, J. Rämö, A. Sarpola, J. Tanskanen, Removal of different NOM fractions from surface water with aluminium formate, Sep. Purif. Technol. 118 (2013) 842-846.

[14] M. Väänänen, L. Kupiainen, J. Rämö, A. Sarpola, J. Tanskanen, Speciation and coagulation performance of novel coagulant - Aluminium formate. Sep. Purif. Technol. 86 (2012) 242-247. 
[15] F. AlMubaddal, K. AlRumaihi, A. Ajbar, Performance optimization of coagulation/flocculation in the treatment of wastewater from a polyvinyl chloride plant. J. Hazard. Mater. 161 (2009) 431438.

[16] F. Sher, A. Matik, H. Liu, Industrial polymer effluent treatment by chemical coagulation and flocculation. J. Environ. Chem. Eng. 1 (2013) 684-689.

[17] J. Gregory, Particles in Water, CRC Press, Taylor \& Francis Group, Boca Raton, 2006.

[18] J. Duan, J. Gregory, Coagulation with hydrolysing metal salts. Adv. Colloid Interface Sci. 100102 (2003) 475-502. 